University of Nebraska - Lincoln

DigitalCommons@University of Nebraska - Lincoln

U.S. Environmental Protection Agency Papers

U.S. Environmental Protection Agency

2014

Scale-dependency of LiDAR derived terrain attributes in quantitative soil-landscape modeling: Effects of grid resolution vs. neighborhood extent

J.J. Maynard

USDA-Agricultural Research Service, jmaynard@nmsu.com

M.J. Johnson

U.S. Environmental Protection Agency

Follow this and additional works at: http:// digitalcommons.unl.edu/usepapapers

Maynard, J. J. and Johnson, M. J., "Scale-dependency of LiDAR derived terrain attributes in quantitative soil-landscape modeling: Effects of grid resolution vs. neighborhood extent" (2014). U.S. Environmental Protection Agency Papers. 217.

http://digitalcommons.unl.edu/usepapapers/217

This Article is brought to you for free and open access by the U.S. Environmental Protection Agency at DigitalCommons@University of Nebraska -

Lincoln. It has been accepted for inclusion in U.S. Environmental Protection Agency Papers by an authorized administrator of

DigitalCommons@University of Nebraska - Lincoln. 


\title{
Scale-dependency of LiDAR derived terrain attributes in quantitative soil-landscape modeling: Effects of grid resolution vs. neighborhood extent
}

\author{
J.J. Maynard ${ }^{\text {a,* }}$, M.G. Johnson ${ }^{\text {b }}$ \\ a USDA-Agricultural Research Service, P.O. Box 30003, MSC 3JER, Las Cruces, NM 88003, United States \\ ${ }^{\mathrm{b}}$ U.S. Environmental Protection Agency, 200 SW 35th Street, Corvallis, OR 97333, United States
}

\section{A R T I C L E I N F O}

\section{Article history:}

Received 23 May 2013

Received in revised form 20 March 2014

Accepted 22 March 2014

Available online xxxx

\section{Keywords:}

LiDAR

Digital elevation model

Grid resolution

Neighborhood extent

Scale effects

Terrain attributes

Soil landscape modeling

\begin{abstract}
A B S T R A C T
Quantifying the spatial distribution of soil properties is essential for ecological and environmental modeling at the landscape scale. Terrain attributes are among the primary covariates in soil-landscape models due to their control on energy and mass fluxes, which in turn control the spatial distribution of soil properties and processes. While numerous studies have demonstrated the importance of terrain attributes for predicting landscape-scale soil variability, considerable uncertainty exists as to the scale-dependency of light detection and ranging (LiDAR) derived terrain attributes on the accuracy of soil-landscape model predictions. Thirty five pedons were sampled by genetic horizon in a 2300 ha forested watershed and three soil properties (clay, sum of bases, and total carbon), representing dominant pedogenic processes within the watershed were analyzed. Soil properties were used as dependent variables and terrain attributes, calculated from LiDAR derived DEMs of various grid resolutions (ranging from 5 to $50 \mathrm{~m}$ ) and neighborhood extents (ranging from 15 to $350 \mathrm{~m}$ ), were used as predictor variables in ordinary least-squares (OLS) regression models. Results from this study show that model predictions exhibit a strong scale-dependency, with percent clay, sum of bases, and total carbon having the highest $\mathrm{R}^{2}$-adj and lowest root mean square error (RMSE) at coarse neighborhood extents (i.e., 150 to $300 \mathrm{~m}$ ) both between soil variables and across soil depths. Furthermore, in certain instances grid resolution was also shown to affect soil-terrain correlations, although to a lesser degree than neighborhood extent. In many cases fine to moderate scale grid resolutions (i.e., $<30 \mathrm{~m}$ ) more accurately represented terrain features, resulting in higher correlations to soil properties at fixed neighborhood extents relative to course grid resolutions. Additionally, these results show that fine scale topographic information (i.e., 1 to $5 \mathrm{~m}$ ) does not necessarily provide a stronger predictor of soil spatial variability relative to moderate scale information. This study provides a robust framework for investigating pedogeomorphological processes on a landscape scale through examination of the scale dependency of modeled terrain attributes in quantitative soil-landscape modeling.
\end{abstract}

Published by Elsevier B.V.

\section{Introduction}

Within the past century, dramatic increases in population growth combined with rapid industrialization have greatly affected the way in which natural lands are used and managed. Growing anthropogenic pressures resulting from these trends, including urbanization, environmental pollution and the increasing effects of climate change, are altering the structure and function of many ecosystems and the resulting services they provide (Rapport et al., 1998). Consequently, there is a growing need to quantify the biophysical properties of landscapes

Abbreviations: LiDAR, light detection and ranging; DEM, digital elevation model; OLS, ordinary least squares; RMSE, root mean square error; NRCS, Natural Resources Conservation Service.

* Corresponding author. Tel.: +1 5756462660

E-mail address: jmaynard@nmsu.com (J.J. Maynard). from a local- to regional- to national-scale, to promote sustainable resource management.

Soils play a fundamental role in transmitting, storing and reacting with natural and human-introduced materials, and thus exert a dominant control on the hydrologic and geochemical processes which drive ecosystem function. Consequently, quantifying the spatial distribution of soil properties is essential for ecological and environmental modeling at the landscape scale. To meet this challenge, soil-landscape modeling has emerged as a methodology for understanding the spatial distribution of soils and their coevolving landscapes (Scull et al., 2003). With the advent of geographic information systems (GIS), the greater accessibility of high resolution remotely sensed data (LiDAR, hyper-spectral/spatial imagery), and the development of spatial statistical techniques, it is now possible to integrate a variety of environmental factors that correlate with soil properties, thus greatly improving our ability to predict their spatial distribution. 
Among soil forming factors, topography and modeled terrain attributes have been used extensively to establish statistical associations with soil properties, including soil organic carbon (Arrouays et al., 1995; Gessler et al., 2000; McKenzie and Ryan, 1999; Moore et al., 1993; Ryan et al., 2000), texture (Arrouays et al., 1995; Bishop and Minasny, 2006; De Bruin, 1998; McKenzie and Austin, 1993; Moore et al., 1993), and soil depth (Gessler et al., 1995; McKenzie and Ryan, 1999; Park et al., 2001; Ryan et al., 2000; Sinowski and Auerswald, 1999; Walker et al., 1968). In many cases, terrain attributes provide the best indicator of soil properties in places where the variation of other environmental factors (e.g., climate, lithology, land-use) is relatively small (e.g., mountainous terrain) (Moore et al., 1993; Park and Burt, 2002). Soil development often occurs in response to the way in which water and soil materials move through and over the land surface, which in turn is controlled by local topography (Huggett, 1975). Thus, terrain analysis is most useful in landscapes where topographic shape is strongly related to the processes driving soil formation (McKenzie et al., 2000).

With the increasing availability of LiDAR derived DEMs, there has been a general assumption that terrain attributes derived at fine spatial resolutions will produce stronger correlations to soil properties, however, several recent studies have shown that this may not be true (Kim and Zheng, 2011; Park et al., 2009; Roecker and Thompson, 2010). The spatial relationship that exists between soil properties and terrain attributes is driven by underlying pedogeomorphological processes operating across a range of spatial scales. Most pedogeomorphological processes exhibit a strong scale dependency which results in the spatial pattern and range of soil properties across a landscape (Grunwald, 2006). Therefore, quantifying the scale dependent relationship between soil properties and terrain attributes is important in determining the optimal scale at which terrain attributes most accurately represent soil-landscape processes.

The spatial scale of terrain attributes is related to both the grid resolution of the DEM used and the neighborhood extent or size of the window over which they are calculated. While there have been many studies that have examined the effect of grid size on derived terrain attributes and their relationship to various biophysical landscape attributes (Vaze et al., 2010; Wechsler, 2007 and references therein) and soil properties (Anderson et al., 2006; Kim and Zheng, 2011; Park et al., 2009; Smith et al., 2006; Thompson et al., 2001), most of these studies calculate terrain attributes from adjacent grid cells in a 3 by 3 moving window. However, with this conventional approach, as the grid-size increases the neighborhood extent is also increased, thus making it impossible to differentiate between the effects of changing grid-size and changing neighborhood extent. Several recent studies have explicitly controlled for these two scale effects, allowing for the examination of each scale effect independently (Roecker and Thompson, 2010; Smith et al., 2006). When the grid resolution of a DEM is increased, there is a loss of topographic detail as the values from smaller resolution grid cells, representing micro-topography, are aggregated producing an average value for the larger grid area. Although this approach allows one to calculate terrain attributes at the spatial scale at which soil properties vary, the resulting decrease in accuracy may negatively affect soil-topography correlations. An alternative approach, first proposed by Wood (1996) and more recently promoted by Roecker and Thompson (2010), is to maintain a small grid resolution (e.g., 1-5 m) while varying the neighborhood extent of terrain attributes to match the spatial scale of the property being modeled, thus more accurately representing soil-landscape processes. Several studies have demonstrated the importance of neighborhood extent in influencing soil-landscape relationships (Park et al., 2001; Roecker and Thompson, 2010; Smith et al., 2006).

The main objective of this study is to characterize the scaledependent soil-topography relationships in a forested watershed in Oregon's Coast Range mountains, with an explicit examination of the effects of changing grid resolution versus changing neighborhood extent. The specific objectives are to: (i) examine grid resolution effects while controlling for neighborhood extent, (ii) examine neighborhood extent effects while controlling for grid resolution, and (iii) assess the utility of high resolution terrain data over conventional scale DEM resolutions (e.g., 10-30 m) in predicting soil properties.

\section{Materials and methods}

\subsection{Study site}

The study was conducted in the Panther Creek Watershed, located on the east side of the Oregon Coast Range Mountains, USA. The Panther Creek study area $\left(45^{\circ} 18^{\prime} \mathrm{N}, 123^{\circ} 21^{\prime} \mathrm{W}\right)$ is approximately 2300 ha and the elevation ranges from 100 to $700 \mathrm{~m}$. Slopes and drainage basins are consistently steep throughout the watershed, approaching $90^{\circ}$ in some areas. The Panther Creek Watershed has a marine-influenced climate with cold, moist winters and warm dry summers, with approximately $70 \%$ of precipitation occurring between November and March. At the higher elevations (i.e., 400-700 m), the watershed has a udic moisture regime with mean annual precipitation (MAP) ranging from 200 to $250 \mathrm{~cm}$, and at lower elevations (i.e., $70-400 \mathrm{~m}$ ) a xeric moisture regime, with MAP ranging from 100 to $150 \mathrm{~cm}$. Mean annual temperature in the study area is $12{ }^{\circ} \mathrm{C}$, with the temperature regime ranging from frigid at higher elevations to mesic at lower elevations. The soils in the western portion of the study area (high elevation areas) are formed from basalt bedrock (diabase), transitioning to the east where soils are formed over basalt and sedimentary bedrock (deep-water marine siltstone/sandstone) at lower elevations. Soils within the watershed are predominantly well-drained silt loam, silty clay loam, and clay loam soils. The dominant taxonomic classifications are Typic Haplohumults, Xeric Palehumults, and Andic Dystrudepts. Vegetation within the watershed is dominated by planted stands of Douglas-fir (Pseudotsuga menziesii), with significant amounts of western hemlock (Tsuga heterophylla), western red cedar (Thuja plicata), grand fir (Abies grandis), red alder (Alnus rubra), and big leaf maple (Acer macrophyllum). The study area is actively managed for timber production with an average rotation age from 40 to 60 years, resulting in a patchwork of even-aged Douglas-fir stands ranging from recent clear-cuts to mature second-growth forests (Fig. 1). Within the watershed, the land holdings are split between private (54\%) and public (46\%) ownership resulting in a range of different land-use practices and long-term management goals.

\subsection{Soil sampling and analysis}

Thirty-five soil sampling locations were selected by a purposive sampling design driven by pre-stratification of the watershed into homogeneous landscape units using multiple geospatial data layers (e.g., geological information, climatic data, aerial photography, land ownership maps, vegetation maps). At each of the thirty-five sampling locations, a single pedon was described and sampled by NRCS soil scientists, and sent off for analysis of soil physical and chemical properties of the $<2-\mathrm{mm}$ soil material at the NRCS National Soil Survey Laboratory (Lincoln, NE), following standard laboratory methods (Burt, 2004). The $<2$-mm soil fraction was dispersed for particle-size analysis following removal of organic matter and soluble salts. The sand fraction was separated by wet sieving. The silt and clay fractions were measured by the pipette method. Exchangeable cations $\left(\mathrm{Ca}^{2+}, \mathrm{Mg}^{2+}, \mathrm{K}^{+}, \mathrm{Na}^{+}\right)$ were extracted with ammonium acetate $(1 \mathrm{~N}, \mathrm{pH} 7)$ and measured by an atomic absorption spectrophotometer (AAS). Total C (TC) analysis was performed by dry combustion.

Each soil pedon was sampled and described by genetic horizon, however, to facilitate comparison between profiles we segmented each profile into $1 \mathrm{~cm}$ slices and then aggregated the slices (weighted average) using a standardized soil depth structure consisting of two depth increments: 0 to 20 and 20 to $50 \mathrm{~cm}$. The segmentation procedure 


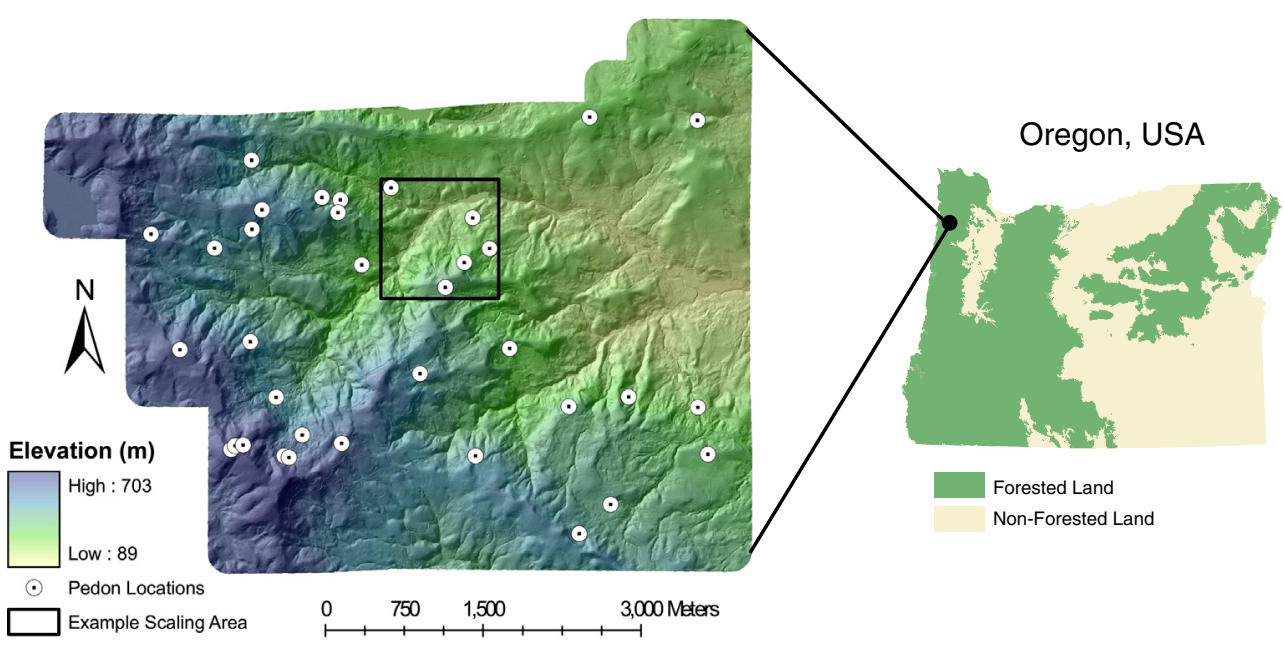

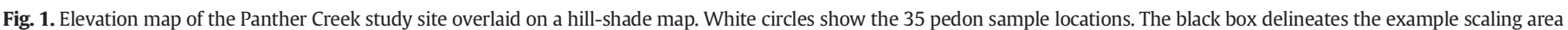
used to illustrate differences in DEM resolution (see Fig. 6).

involved fitting an equal-area or mass-preserving quadratic spline across the discrete set of genetic horizon values for each soil property, producing a continuous depth function segmented at $1 \mathrm{~cm}$ intervals (Bishop et al., 1999; Malone et al., 2009). Mean values across the two standardized soil depth intervals (0-20 and 20-50) were calculated for each property, thus allowing for comparisons between soil profiles with differing soil genetic horizon thicknesses. The segmenting algorithm was implemented using the 'GSIF' and 'aqp' packages for $\mathrm{R}$ (Beaudette et al., 2013).

\subsection{Terrain analysis}

Airborne-based LiDAR for the Panther Creek Cooperative Research Program was acquired using a Leica ALS50-Phase II on March 28, 2009 during leaf-off conditions by Watershed Sciences, Inc. LiDAR imagery was collected $\pm 14^{\circ}$ off-nadir, with $100 \%$ flight line overlay and a pulse density of $\geq 8$ pulses $\mathrm{m}^{-2}$. Ground densities averaged approximately 0.7 pulses $\mathrm{m}^{-2}$. Extensive QA/QC was performed to identify and correct source topographic data errors. A $1 \mathrm{~m}$ ground-based DEM was then generated using Triangulated Irregular Network (TIN) interpolation of all ground returns, and used to generate coarser resolution DEMs for subsequent scaling analysis. DEM resampling was done using the 'raster' package for R (Hijmans and Van Etten, 2011), creating 10 coarser resolution DEMs (i.e., 5, 10, 15, 20, 25, 30, 35, 40, 45 and $50 \mathrm{~m}$ grid resolution) using mean resampling. The terrain attributes calculated in this study included elevation (m), slope gradient (degrees), aspect (degrees), profile curvature (degrees $/ \mathrm{m}$ ), plan curvature (degrees $/ \mathrm{m}$ ), longitudinal curvature (degrees $/ \mathrm{m}$ ), cross-sectional curvature (degrees/m), minimum curvature (degrees/m), and maximum curvature (degrees $/ \mathrm{m}$ ). Since aspect is a circular measure, it was first cosine transformed with a $90^{\circ}$ phase shift $\left(\cos \left[\alpha-90^{\circ}\right]\right)$ before being incorporated in regression modeling. This results in a maximum of unity at the east and minimum of minus unity at the west. Previous work by Beers et al. (1966) observed that southwest aspects are often the most severe sites of forest regeneration and growth. Through iteratively testing different offsets in simple linear regression models with soil properties, the strongest correlations were produced with a $90^{\circ}$ phase shift which corresponds to the strong east-west elevation gradient within the watershed. In digital terrain analysis, the first- and secondorder derivatives of a DEM (slope and curvatures) are the basic components used to correlate the spatial distribution of soil properties and classes. Terrain curvatures are defined as the rate of change of the slope in a particular direction and relate to the accumulation or dispersion of surface and subsurface water. Thus, terrain curvature often provides a strong predictor of soil development through its effect on the spatial distribution of soil properties influenced by the flux of water and materials horizontally from upslope areas or vertically from surface soil horizons. Slope, aspect, and the six different curvature parameters were calculated using the r.param.scale GRASS module (Wood, 1996). This module calculates terrain attributes by fitting a quadratic polynomial approximation over the values in an n-by-n pixel moving window across the DEM. The nine terrain attributes were calculated from the ten different DEM resolutions $(5,10,15,20$, $25,30,35,40,45$ and $50 \mathrm{~m}$ ), adjusting the neighborhood extent at each DEM resolution to a maximum neighborhood extent of approximately $350 \mathrm{~m}$ (Fig. 3). This resulted in 65 unique grid resolutionneighborhood extent combinations, producing 585 terrain attributes. This network of grid resolution-neighborhood extent combinations allows for the explicit examination of: (i) grid resolution effects while controlling for neighborhood extent, (ii) neighborhood extent effects while controlling for grid resolution, and (iii) grid resolution effects using a conventional approach (i.e., $3 \times 3$ moving window) where both grid resolution and neighborhood extent change. These three approaches are illustrated in Fig. 2. Terrain attributes and soil properties used in this study are presented in Tables 1 and 2, respectively.

\subsection{Statistical analysis}

The distribution of soil properties across a landscape is dictated by fundamental processes which operate at varying spatial scales (Grunwald, 2006). We selected three soil properties that represent dominant pedogenic processes occurring within the watershed, including mineral weathering represented by clay, cation cycling represented by sum of bases $\left(\mathrm{Ca}^{2+}+\mathrm{Mg}^{2+}+\mathrm{K}^{+}+\mathrm{Na}^{+}\right)$, and organic matter-metal cycling represented by total carbon. All soil properties were tested for normality using the Shapiro-Wilk normality test. All soil properties that deviated from normality were transformed using the Box-Cox transformation. Ordinary least squares (OLS) models where used to examine the correlation between soil properties and a suite of terrain attributes calculated at different grid resolutions and neighborhood extents. We calculated an adjusted R-squared ( $R^{2}$-adj) to adjust for our small sample size and large number of predictor variables. All statistical analyses were conducted using R software.

\section{Results}

A strong east-to-west elevation and precipitation gradient exists within the watershed, producing a range of soil forming environments and resulting soil properties. Additionally, the presence of mixed geology (basalt and sedimentary parent material), further contributes 
a) Clay

b) Sum of Bases

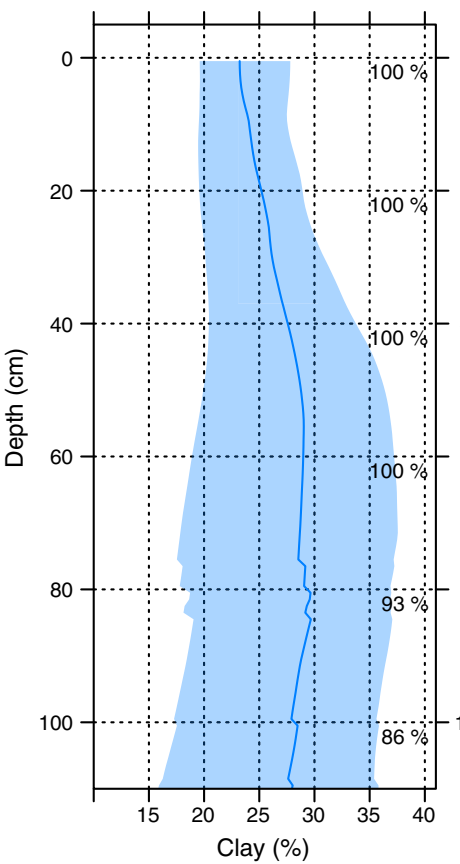

\section{b)}

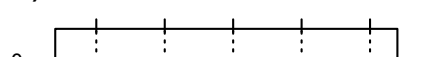

c) Total Carbon
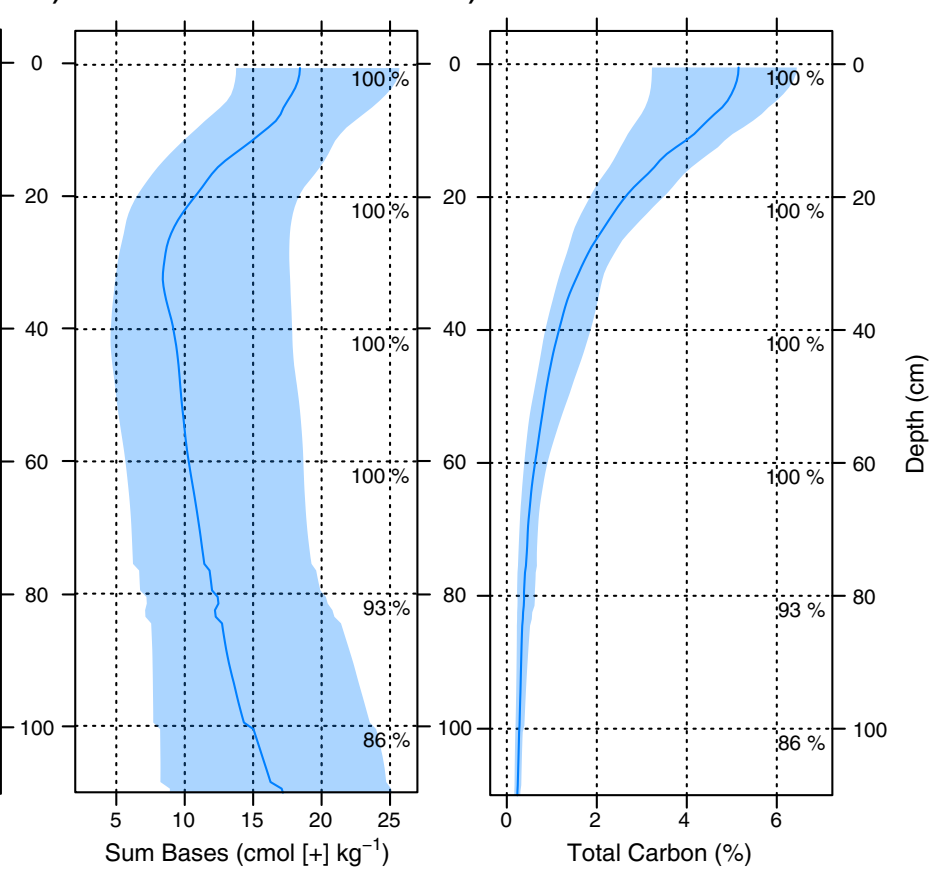

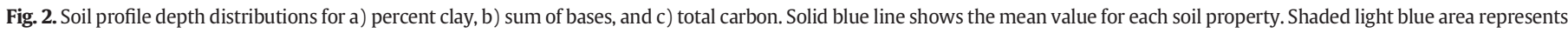

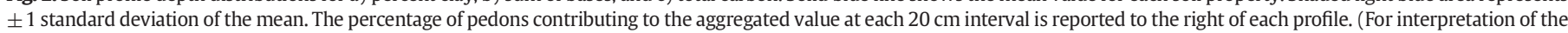
references to color in this figure legend, the reader is referred to the web version of this article.)

to the diversity of soil properties and types within the watershed. Soil physical and chemical properties at the two depth intervals ( 0 to 20 and 20 to $50 \mathrm{~cm}$ ) for 35 pedons sampled across the Panther Creek Watershed are listed in Table 2. In general, soils within the watershed have a high percentage of clay (mean \pm sd. [\%]: $24.7 \pm 9.0$ at $0-$ $20 \mathrm{~cm} ; 26.7 \pm 9.9$ at $20-50 \mathrm{~cm}$ ); have moderate-to-high concentrations of bases (mean $\pm \mathrm{sd}$. $\left[\mathrm{cmol}(+) \mathrm{kg}^{-1}\right]: 17.0 \pm 8.1$ at $0-20 \mathrm{~cm} ; 12.6 \pm$ 10.3 at $20-50 \mathrm{~cm}$ ); and have moderate concentrations of soil organic carbon (mean \pm sd. [\%]:4.1 \pm 1.7 at $0-20 \mathrm{~cm} ; 1.7 \pm 0.7$ at $20-50 \mathrm{~cm}$ ) (Table 2). Depth distribution profiles for clay, sum of bases, and total carbon are presented in Fig. 2, showing the mean \pm standard deviation of each property from the 35 pedons segmented at $1 \mathrm{~cm}$ increments. Depth profiles for clay and sum of bases show considerable variability between pedons in both surface and subsurface depths, while total carbon shows only moderate variability in the surface layer $(0-20 \mathrm{~cm})$ and decreasing variation in subsurface depths (Fig. 3). There was some variation in soil profile depths across the 35 soil pedons, with 33 of 35 pedons (93\%) extending beyond $80 \mathrm{~cm}$ and only 30 of 35 pedons (86\%) extending beyond $100 \mathrm{~cm}$ (Fig. 3). Consequently, calculated depth averages for some soil properties appear to be invariant with depth. For example, average clay percentage shows little change with depth due to clay rich B horizons that can extend well below
$100 \mathrm{~cm}$. Our use of depth intervals vs. genetic horizon allows us to model soil properties across a landscape with varying total soil profile depths.

The influence of spatial scale on the characterization of terrain attributes, that is the effects of changing grid resolution vs. the effects of changing neighborhood extent, are illustrated in Figs. 4 and 5. This analysis was conducted within an example scaling area, illustrated in Fig. 1. The effects of increasing grid resolution while setting a constant neighborhood extent $(150 \mathrm{~m})$ can be seen for both slope gradient (Fig. $4 \mathrm{a}-\mathrm{c}$ ) and profile curvature (Fig. $4 \mathrm{f}-\mathrm{g}$ ). As the grid resolution increases from 5 to $50 \mathrm{~m}$ the fine scale spatial patterns present in the $5 \mathrm{~m}$ maps become increasingly less discernible (Fig. $4 \mathrm{a}-\mathrm{c}, \mathrm{f}-\mathrm{g}$ ). The distribution of slope (Fig. 4d) and profile curvature (Fig. 4i) values is similar across the range of grid resolutions with similar median values and interquartile ranges. At the $50 \mathrm{~m}$ resolution, there is a slight narrowing of the interquartile range for slope gradient and an increasing number of outliers for profile curvature. A transect of values extracted across the example scaling area shows a strong concordance of values at 5 and $30 \mathrm{~m}$ resolutions. At the $50 \mathrm{~m}$ grid resolution, however, a higher degree of deviation from the values obtained at fine scale grid resolutions emerges for both slope gradient and profile curvature (Fig. $4 \mathrm{e}$ and j).

Table 1

Terrain attributes calculated from LiDAR derived DEM of the Panther Creek Watershed.

\begin{tabular}{|c|c|c|c|}
\hline Attribute & Unit & Variable & Description and methods \\
\hline Elevation & $\mathrm{m}$ & elev & Vertical distance from mean sea level, indicates potential energy. \\
\hline Slope gradient & Degrees & slope & Magnitude of maximum gradient, indicates overland and subsurface flow rate and runoff velocity. \\
\hline Aspect & Degrees & aspect & Direction of maximum gradient, indicates solar irradiation. \\
\hline Profile curvature & Degrees/m & profc & Influences flow acceleration, erosion/deposition rate \\
\hline Plan curvature & Degrees/m & planc & Influences flow convergence and divergence, soil water content, soil characteristics \\
\hline Longitudinal curvature & Degrees/m & longc & Without physical meaning, explains the terrain in a similar way to plan profile and plan curature \\
\hline Cross-sectional curvature & Degrees/m & crosc & Without physical meaning, complimentary to longitudinal curvature \\
\hline
\end{tabular}


Table 2

Summary of selected soil properties from 35 pedons within the Panther Creek watershed.

\begin{tabular}{lccccccc}
\hline Variable $^{\dagger}$ & Depth $(\mathrm{cm})$ & Mean & Min & Max & SD & Skew & Kurtosis \\
\hline Clay (\%) & & & & & & & \\
& $0-20$ & 24.70 & 9.61 & 60.17 & 9.04 & 1.61 & 4.69 \\
& $20-50$ & 26.65 & 8.53 & 53.71 & 9.93 & 0.31 & 0.24 \\
& & & & & & \\
Sum-Bases (cmol (+) $\left.\mathrm{kg}^{-1}\right)$ & & & & & & \\
& $0-20$ & 17.00 & 4.28 & 37.64 & 8.13 & 0.88 & 0.11 \\
& $20-50$ & 12.62 & 2.89 & 40.72 & 10.25 & 1.32 & 0.89 \\
TC $(\%)$ & & & & & & & \\
& $0-20$ & 4.06 & 1.83 & 6.61 & 1.42 & 0.03 & -1.13 \\
& $20-50$ & 1.68 & 0.55 & 2.33 & 0.74 & 0.80 & -0.10 \\
\hline
\end{tabular}

$\dagger$ TC, total carbon.

The effects of increasing neighborhood extent while setting a constant grid resolution $(5 \mathrm{~m})$ can be seen for both slope gradient (Fig. 5a-c) and profile curvature (Fig. 5f-g). As the neighborhood extent increases from 15 to $345 \mathrm{~m}$, there is a substantial smoothing of the terrain values (Fig. $5 \mathrm{a}-\mathrm{c}, \mathrm{f}-\mathrm{g}$ ). This smoothing trend is further illustrated by boxplots of the distribution of slope gradient and profile curvature values (Fig. $5 \mathrm{~d}$ and $\mathrm{i}$ ). As neighborhood extent increases, the interquartile range of slope values across the study area decreases slightly (Fig. 5d). The interquartile range of profile curvature values, however, decreases dramatically and outliers become less extreme as neighborhood extent increases (Fig. 5i). This illustrates the greater effect of changing neighborhood extent on terrain attributes calculated from the 2nd derivative of a DEM (curvature) relative to 1 st derivative attributes (slope). The transect of values extracted across the example scaling area further shows how increasing neighborhood extent results in an averaging or smoothing of the data (Fig. 5e and $\mathrm{j}$ ). The transect of slope values shows that as neighborhood extent is increased from 15 to $115 \mathrm{~m}$, there is a substantial loss in fine scale topographic detail, preserving only larger scale trends in percent slope. As the neighborhood extent is increased to $345 \mathrm{~m}$, however, there is an almost complete loss of both fine-to-medium scale topographic details, preserving only very coarse scale trends (Fig. 5e). These effects are even more pronounced for profile curvature where the range of values, representing

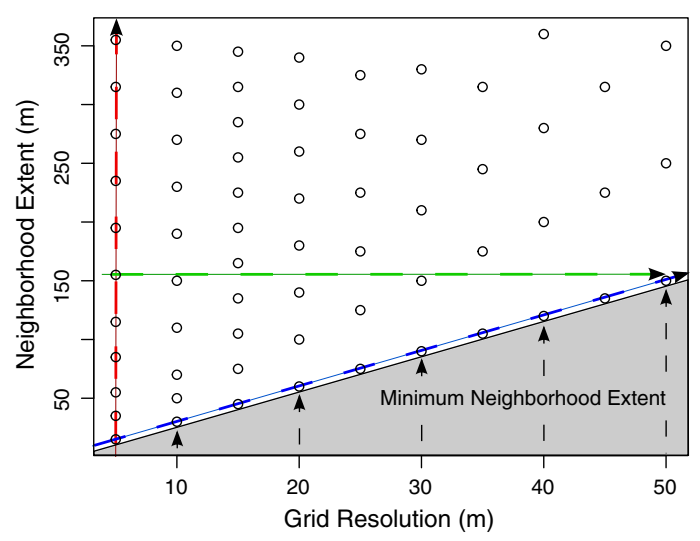

Fig. 3. Schematic of sampling grid illustrating the grid resolution-neighborhood extent combinations used in this study. A subsample of possible neighborhood extents at 5 and $10 \mathrm{~m}$ grid resolutions were selected to minimize the number of samples analyzed. The gray area represents the minimum neighborhood extent possible for each grid resolution. The horizontal green dashed line shows sampling to examine grid resolution effects by fixing the neighborhood extent at $150 \mathrm{~m}$. The vertical red dashed line shows sampling to examine neighborhood extent effects by fixing the grid resolution at $5 \mathrm{~m}$. The diagonal blue dashed line shows sampling under the conventional approach (i.e., $3 \times 3$ grid cell moving window). (For interpretation of the references to color in this figure legend, the reader is referred to the web version of this article.) micro-topographic features, decreases dramatically with increasing neighborhood extent (Fig. 5j). At $345 \mathrm{~m}$ neighborhood extent the range of profile curvature values is so small that little-to-no variation is detectable across the transect (Fig. 5j).

Results from OLS regression modeling revealed a strong scaledependence in the correlation of terrain attributes to soil properties (Figs. 6, 7, and 8). All three soil properties displayed a strong response to changes in neighborhood extent, but only a weak and variable response to grid resolution. Clay had the highest $\mathrm{R}^{2}$-adj and lowest RMSE at neighborhood extents between 150 and $240 \mathrm{~m}$ for both soil depths. Above a neighborhood extent of $240 \mathrm{~m}$ we begin to see a stronger grid resolution effect, with grid resolutions less than $20 \mathrm{~m}$ having the highest $\mathrm{R}^{2}$-adj and lowest RMSE extending until $330 \mathrm{~m}$. Sum of bases had the highest $\mathrm{R}^{2}$-adj and lowest RMSE at neighborhood extents between 200 and $320 \mathrm{~m}$ for both soil depths. TC had the highest $\mathrm{R}^{2}$ adj and lowest RMSE at neighborhood extents between 130 and 250 $\mathrm{m}$ for the 0 to $20 \mathrm{~cm}$ depth and between 200 and 350 for the 20 to $50 \mathrm{~cm}$ depth.

\section{Discussion}

\subsection{Uncoupling scale effects in soil-landscape modeling}

In soil-landscape modeling, DEM derived terrain attributes are used to predict the spatial distribution of soil properties. While numerous studies have demonstrated the importance of terrain attributes for predicting landscape-scale soil variability (Arrouays et al., 1995; Bishop and Minasny, 2006; Chaplot et al., 2000; De Bruin and Stein, 1998; Gessler et al., 1995, 2000; McKenzie and Austin, 1993; McKenzie and Ryan, 1999; Moore et al., 1993; Park et al., 2001; Ryan et al., 2000; Sinowski and Auerswald, 1999), considerable uncertainty exists as to the effects of the spatial scale, that is, the grid resolution and neighborhood extent of derived terrain attribute on the accuracy of soil-landscape model predictions (Anderson et al., 2006; Kim and Zheng, 2011; Park et al., 2009; Roecker and Thompson, 2010). Several studies have shown that the scale of DEM derived terrain attributes contributes to differences in the distribution and representation of soil-landscape attributes (Kim and Zheng, 2011; Park et al., 2009; Thieken et al., 1999; Thompson et al., 2001); Roecker and Thompson, 2010), while other studies have found little difference among soillandscape models due to changing spatial scales (Bishop and Minasny, 2006; Chaplot et al., 2000; Gessler et al., 2000). These differences may be due to the fact that each landscape has a different degree of topographic complexity which in turn affects the spatial scale of the property or process being modeled. Additionally, the spatial scales at which soil properties are expressed across a landscape can occur at a range of scales due to differing combinations and intensities of soil forming factors, thus making the selection of an optimal spatial scale challenging. Consequently, the selection of an appropriate grid resolution and neighborhood extent ultimately depends on the characteristics of the study area (e.g., topographic complexity), as well as the spatial variability and extent of the properties being modeled.

As previously discussed, optimizing soil-landscape models requires identifying and adjusting the scale of terrain attributes to match the scale of the modeled soil-landscape process. This has commonly been achieved by coarsening the horizontal resolution of the DEM to match the spatial scale of the soil process. Several studies have examined the effect of DEM resolution on derived terrain attributes and found that as the resolution becomes coarser, slope gradients tend to decrease, ranges in curvature decrease, and the accuracy of terrain attributes at particular locations tends to decrease (Chaplot et al., 2000; Thompson et al., 2001; Zhang and Montgomery, 1994). Results from these studies are based on the conventional approach (i.e., $3 \times 3$ window) where the neighborhood extent over which terrain attributes are computed changes 

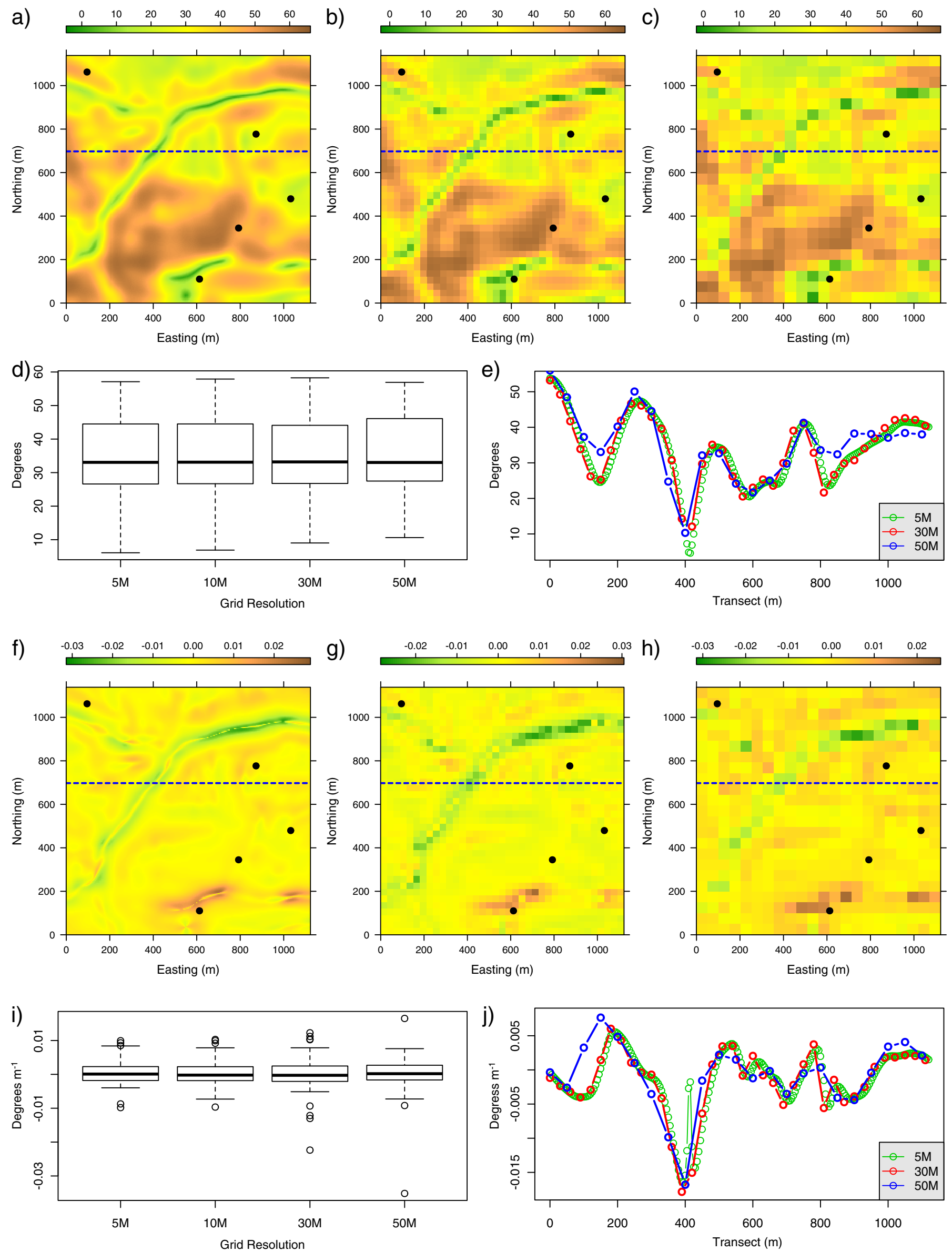
according to the resolution of the DEM. This results in the averaging of elevation values as grid resolutions become coarser and thus an averaging of derived terrain attributes. In this study, using the conventional approach the neighborhood extent for terrain attributes ranged from a $15-\mathrm{m}$ extent in the 5-m DEM to a $150-\mathrm{m}$ extent in the $50-\mathrm{m} \mathrm{DEM}$. It is therefore not surprising that in landscapes with a high degree of topographic complexity, a small grid resolution/ neighborhood extent will fail to accurately characterize larger scale terrain patterns, thus resulting in weak correlations (i.e., low $\mathrm{R}^{2}$-adj, high RMSE). However, while coarsening the DEM resolution to match the spatial scale at which a soil property varies may effectively filter out short-range (i.e., micro-topographic) variation not related to the property being modeled, it may also inadvertently affect the accuracy of terrain information.

Several studies have examined DEM resolution effects on soillandscape model predictions in a range of ecosystem types, including coastal dunes (Kim and Zheng, 2011), agricultural fields (Park et al., 2009), and grazed hillslope environments (Park et al., 2009), and have found that coarse resolution DEMs $(30-50 \mathrm{~m})$ provided the strongest predictions of soil properties. While this approach indicates that soil properties correlate to terrain attributes at coarse spatial scales (30-50 m), it does not indicate whether the coarsening of DEM resolution or the widening of the neighborhood extent is responsible for improved model performance. Several recent studies have shown that changes to terrain attributes due to changing DEM resolution is primarily a result of changes to neighborhood extent and not changes to the grid resolution (Roecker and Thompson, 2010; Smith et al., 2006). Our results confirm these trends where the range in distribution of slope gradient and profile curvature values decreased as neighborhood extent increased (Fig. 5d and i), but experienced very little change as grid resolution became coarser (Fig. 4d and i). While grid resolution effects are small relative to neighborhood extent effects in influencing terrain values, coarser grid resolutions do affect the accuracy of terrain values, as seen in Fig. $4 \mathrm{e}$ and $\mathrm{j}$. As the grid resolution changes from $30 \mathrm{~m}$ to $50 \mathrm{~m}$, there is a noticeable decrease in accuracy of terrain attributes, resulting in a decrease in the strength of the soil-terrain correlations as seen with percent clay at spatial extents ranging from 240-330 (Fig. 6).

Given the loss of accuracy associated with coarsening grid resolution, an alternative approach is to maintain a small grid resolution (e.g., 1-5 m) while varying the neighborhood extent of terrain attributes to match the spatial scale of the property being modeled (Roecker and Thompson, 2010; Wood, 1996). The issue of neighborhood extent on the accuracy of soil predictions was examined by Smith et al. (2006), who concluded that both the grid-size and neighborhood extent of terrain attributes influence the accuracy of digital soil surveys. In their analysis, Smith et al. (2006) found that different DEM resolutions had different optimal (i.e., highest accuracy) neighborhood extents, ranging from 33 to $44 \mathrm{~m}$ on gently rolling landscapes, to 24 to $36 \mathrm{~m}$ on short, steep backslope positions. Roecker and Thompson (2010) concluded that maintaining a small grid-size and varying the neighborhood extent to approximate the scale of the soil processes and resulting properties was preferable over using larger grid-sizes where terrain detail is lost. As previously discussed, when we uncoupled the effects of grid resolution (Figs. 4, and 6-8) and neighborhood extent (Figs. 5-8), two distinct trends emerged for our three modeled soil properties. First, changing neighborhood extent was the dominant factor determining changes in terrain attribute values, which in turn was the dominant factor in optimizing the correlation between soil properties and terrain attributes. Secondly, as grid resolution becomes coarser the accuracy of terrain attributes decreases, thus weakening the correlations between soil properties and terrain attributes. Within this study, there was only a slight decrease in accuracy between fine and moderate resolution DEMs, while there was a more substantial loss in accuracy at courser resolutions (i.e., $50 \mathrm{~m}$ ). Consequently, selecting a moderate resolution DEM such as a $10 \mathrm{~m}$ DEM and adjusting the neighborhood extent to approximate the scale of the soil property or process appears to be the most appropriate approach within this landscape. However, in landscapes with less relief or less topographic complexity, the use of a coarser scale DEMs may also produce accurate results.

\subsection{Scale dependency of soil-topography relationships}

LiDAR data are becoming increasingly available, due in part to a generalized assumption that finer scale topographic data will produce more accurate predictions of landscape attributes. While this may be true for certain landscape attributes (e.g., forest metrics), it remains unclear whether the high horizontal resolution achievable with LiDAR (i.e., $<1-\mathrm{m}$ ) is sufficiently beneficial in soil-landscape modeling given the high cost and high computational requirements associated with its use. Our results, in agreement with others (Kim and Zheng, 2011; Park et al., 2009), do not support this tacit assumption. It is important to note, however, that our different resolution DEMs (i.e.,5, 10, 15, 20, 25, 30, 35, 40, 45 and $50 \mathrm{~m}$ ) were derived from the same LiDAR data and thus have the same vertical accuracy. It has been well established that LiDAR provides significantly higher elevation accuracy relative to traditional DEMs (e.g., USGS-sourced DEMs) (Shi et al., 2012; Vaze et al., 2010), however, the effects of DEM vertical accuracy on soil-landscape modeling have been shown to be less pronounced with coarser resolution DEM derived terrain attributes (Thompson et al., 2001). As a general rule, Thompson et al. (2001) postulate that to properly characterize local topography the vertical precision must increase as the horizontal resolution increases such that the average change in elevation between grid points is greater than that of their vertical precision. Thus, the influence of vertical accuracy on modeling results in areas with high relief is likely minimized due to the large elevation changes between each pixel within a DEM. Given that the soil properties within this landscape had the highest correlations to terrain attributes calculated at coarse spatial extents across a range of grid resolutions, and that loss in the accuracy of terrain values between fine (i.e., 1-5 $\mathrm{m}$ ) and moderate (i.e., $10-20 \mathrm{~m}$ ) resolutions was minimal, the high horizontal resolution and vertical accuracy that LiDAR provides is not necessary for accurate soil-landscape modeling. While the results from this study support this claim, additional analysis is needed for comparing coarser resolution and lower accuracy DEMs (e.g., USGS-sourced DEMs) to LiDAR derived DEMs.

\section{Conclusions}

The scale dependency of the correlation between terrain attributes and soil properties complicates our ability to establish generalized rules or guidelines for soil-landscape modeling. Our results are in agreement with previous studies (Kim and Zheng, 2011; Park et al., 2009; Roecker and Thompson, 2010; Smith et al., 2006) 
a) $\quad \begin{array}{rrrrrrrrr}0 & 10 & 20 & 30 & 40 & 50 & 60 & 70 & 80 \\ 1 & 1 & 1 & 1 & 1 & 1 & 1 & 1 & 1\end{array}$
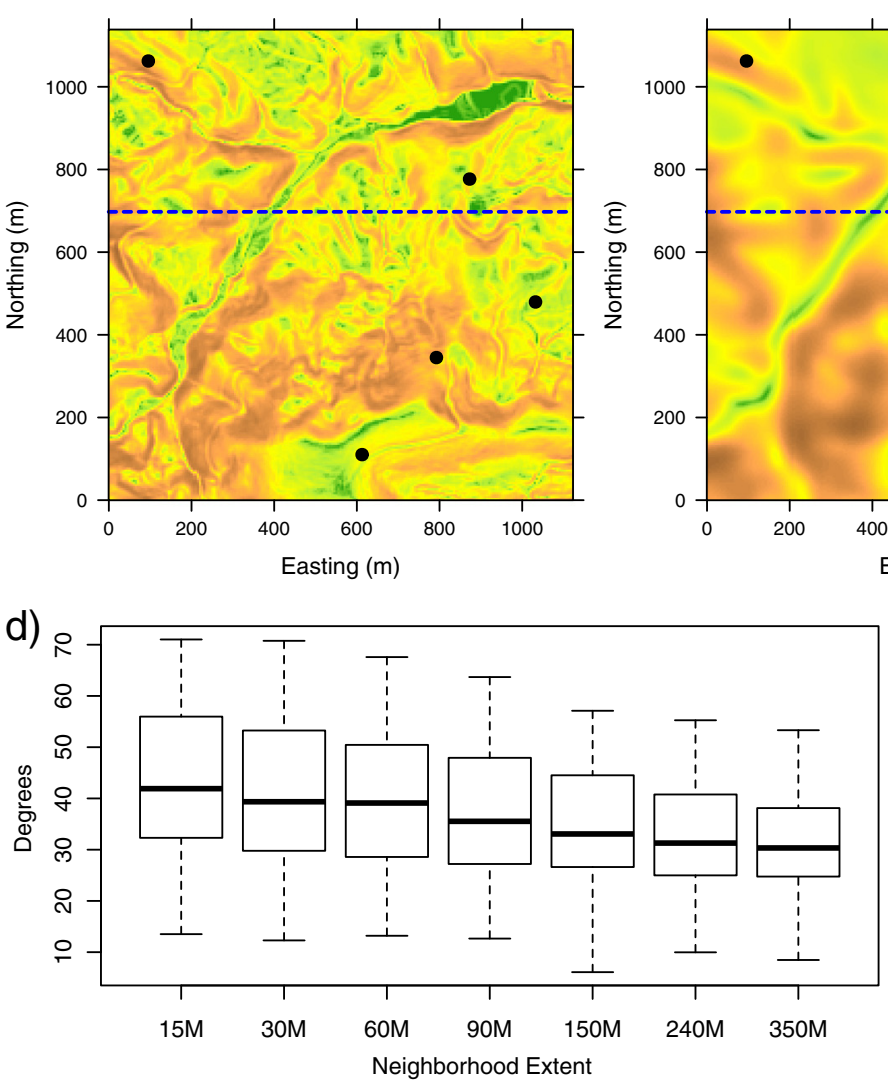

b) $\quad \begin{array}{rrrrrrrr}0 & 10 & 20 & 30 & 40 & 50 & 60 & 70 \\ 1 & 1 & 1 & 1 & 1 & 1 & 1 & 1\end{array}$

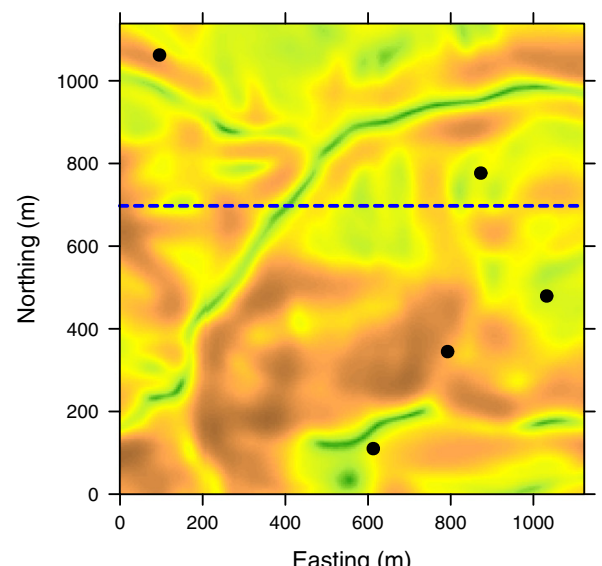

c)

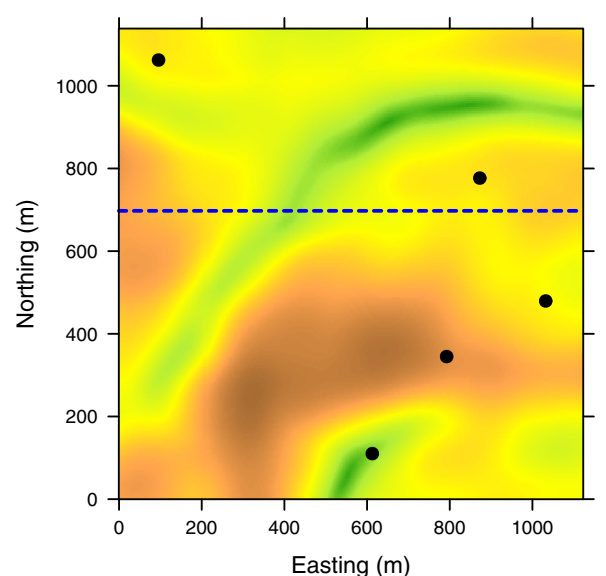

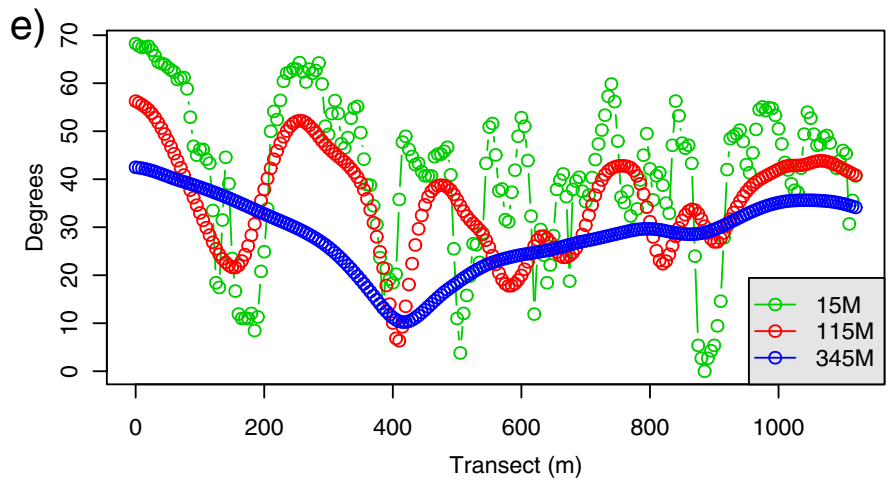

f)

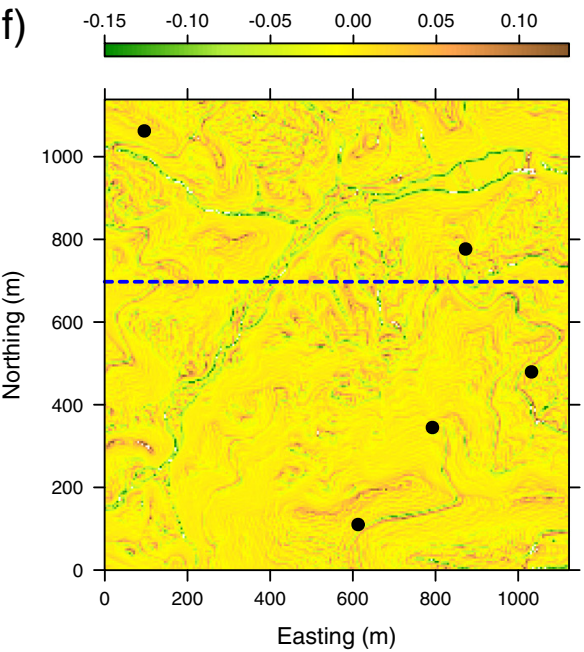

g) $\quad \begin{array}{llllllllll}-0.04 & -0.03 & -0.02 & -0.01 & 0.00 & 0.01 & 0.02 & 0.03\end{array}$

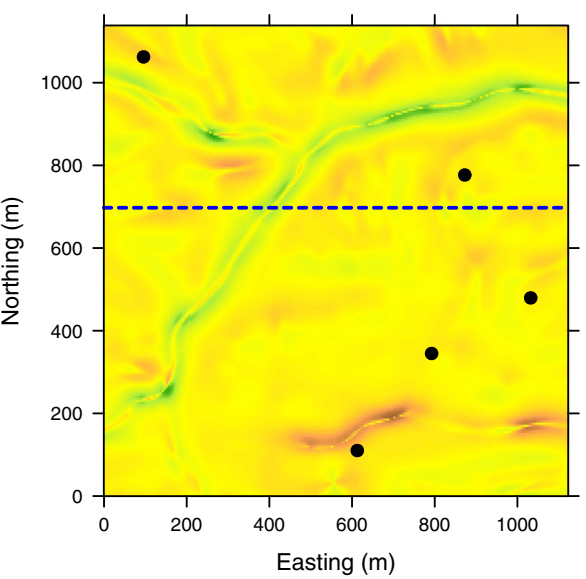

h) $\quad-0.010,-0.006,-0.002,0.0020 .0040 .0060 .008$

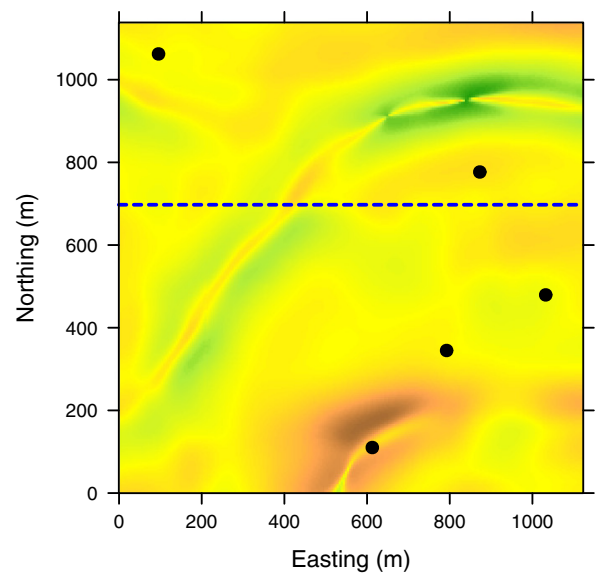

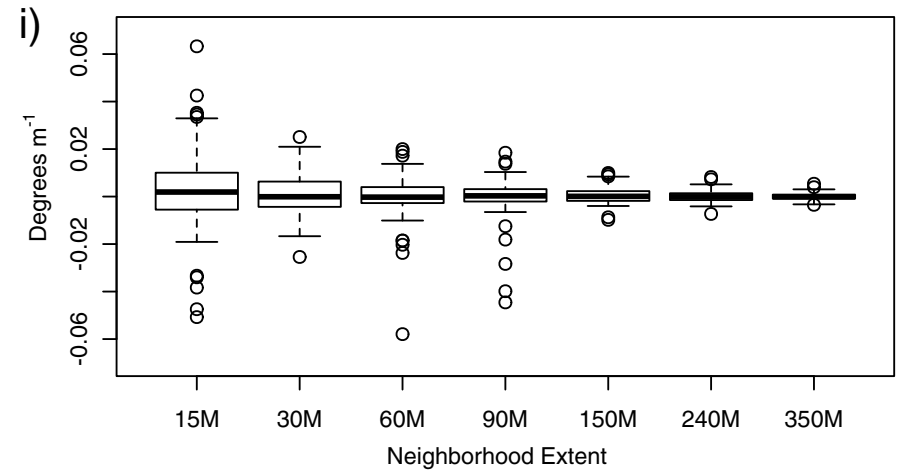

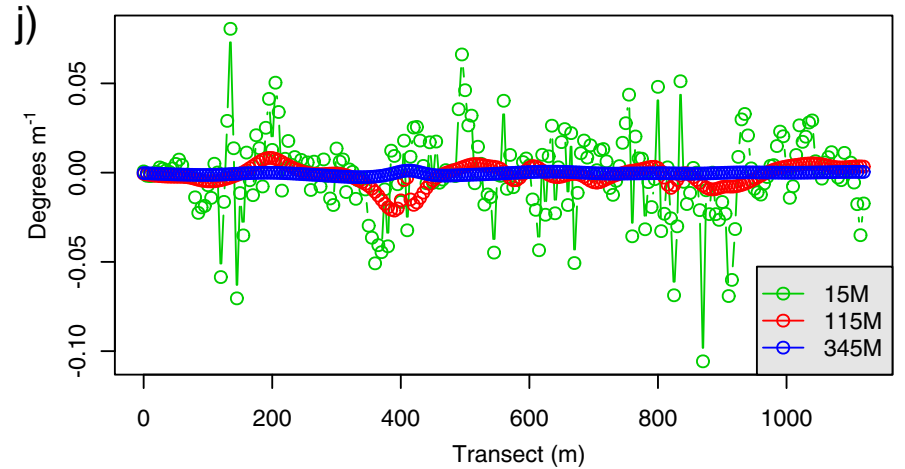


a) Clay $(0-20 \mathrm{~cm}) \mathrm{R}^{2}$ and $\mathrm{R}^{2}$-adj

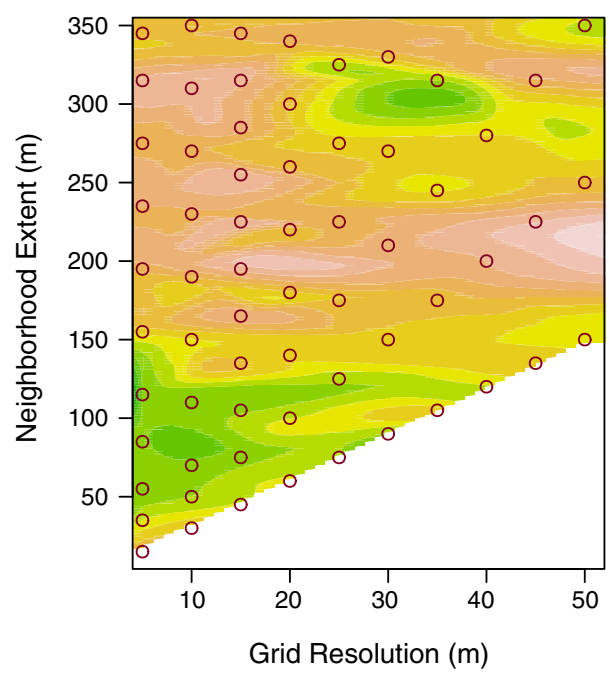

c) Clay $(20-50 \mathrm{~cm}) R^{2}$ and $R^{2}$-adj

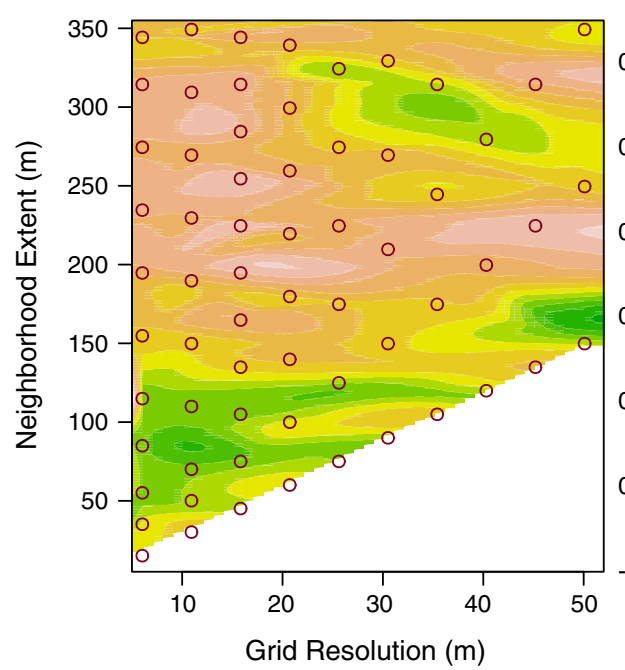

b) Clay $(0-20 \mathrm{~cm})$ RMSE

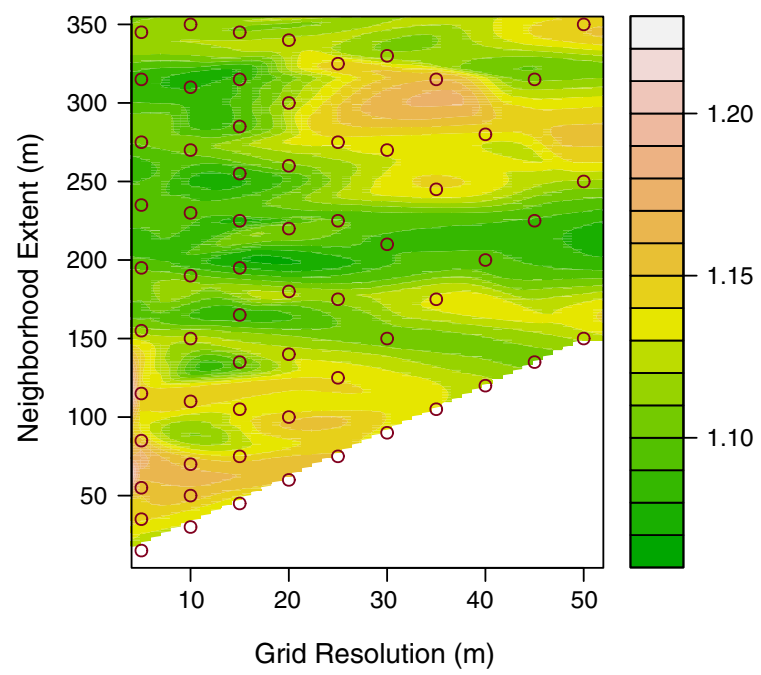

d) Clay $(20-50 \mathrm{~cm})$ RMSE

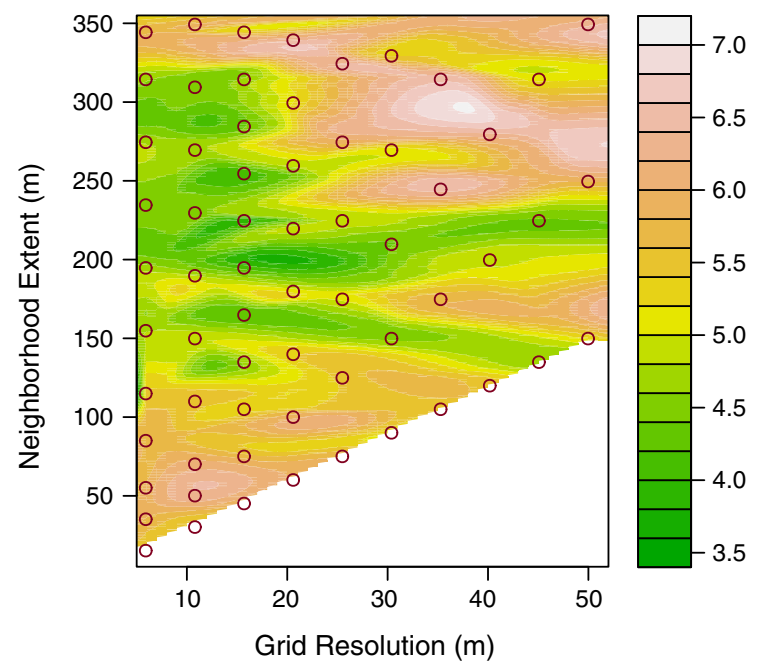

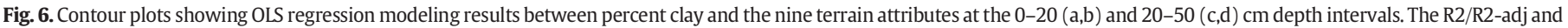
RMSE are presented for the $0-20 \mathrm{~cm}$ (a and b, respectively) and $20-50 \mathrm{~cm}$ (c and d, respectively) depth intervals.

and demonstrate the need to quantify the scale dependency of soil properties within a watershed in order to identify an optimal spatial scale for deriving terrain attributes. Our results show a strong scale dependency in the optimal model prediction both between soil properties and soil depths, with the coarser scale terrain attributes (i.e., 150-250 m neighborhood extent) producing the strongest correlations with soil properties. Additionally, there was only a marginal difference in accuracy of terrain attributes at particular locations between fine (i.e., 1-5 m) and moderate (i.e., 10-20 m) resolution DEMs. This result supports the assertion from previous studies, that LiDAR's high cost, high computational requirements and little to no model improvement severely limit its utility in soil-landscape modeling. Consequently, our results show that optimal correlations between soil properties and terrain attributes can be achieved using moderate resolution DEMs (i.e., $10 \mathrm{~m}$ ) by adjusting the neighborhood extent to match the scale of the property or process being modeled. Our results present a clear pattern despite our small sample size and lack of validation set to test our models (i.e., potential over-fitting of models), and thus provide valuable insight into potential scale effects in soil-landscape modeling. This study demonstrates a robust framework in which to model and interpret the scale dependency of pedogeomorphological processes occurring within a landscape.

\section{Disclaimer}

The information in this document has been funded in part by the U.S. Environmental Protection Agency and the United States Department of

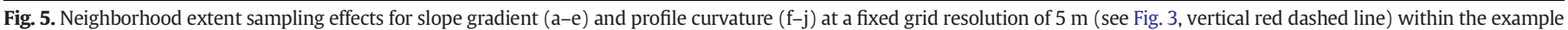

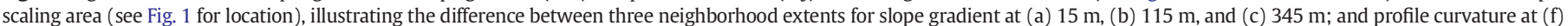

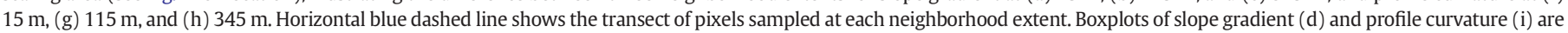

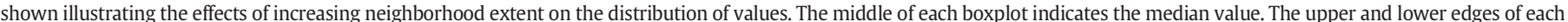

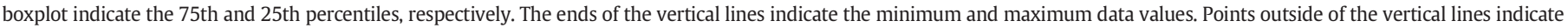

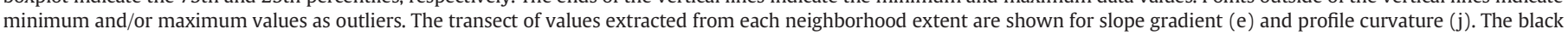
dots in Fig. 5a-c and $\mathrm{f}-\mathrm{h}$ are the location of sampled soil pedons within the example scaling area. 
a) Sum of Bases $(0-20 \mathrm{~cm}) R^{2}$ and $R^{2}$-adj

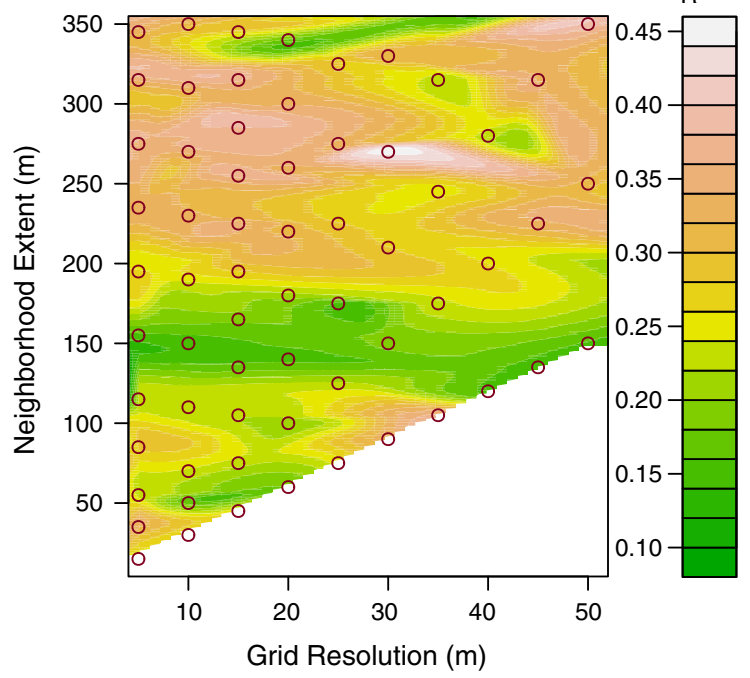

$\mathrm{R}^{2}$-adj

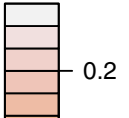

C) Sum of Bases $(20-50 \mathrm{~cm}) R^{2}$ and $R^{2}-a d j$

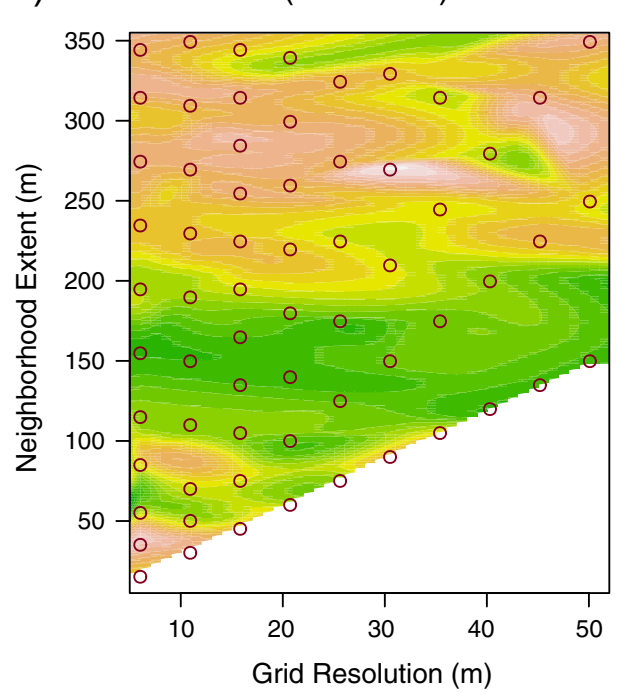

b) Sum of Bases $(0-20 \mathrm{~cm})$ RMSE

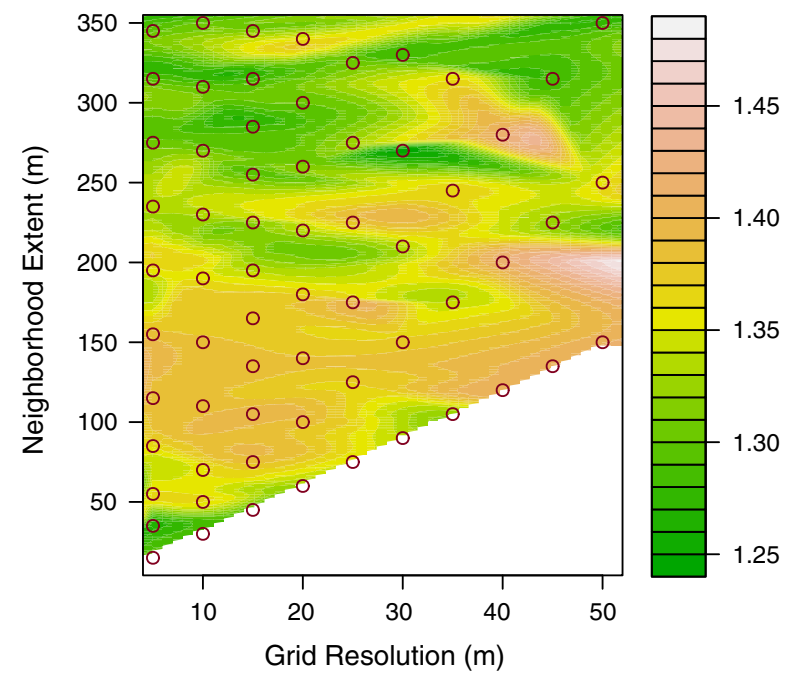

d) Sum of Bases $(20-50 \mathrm{~cm})$ RMSE

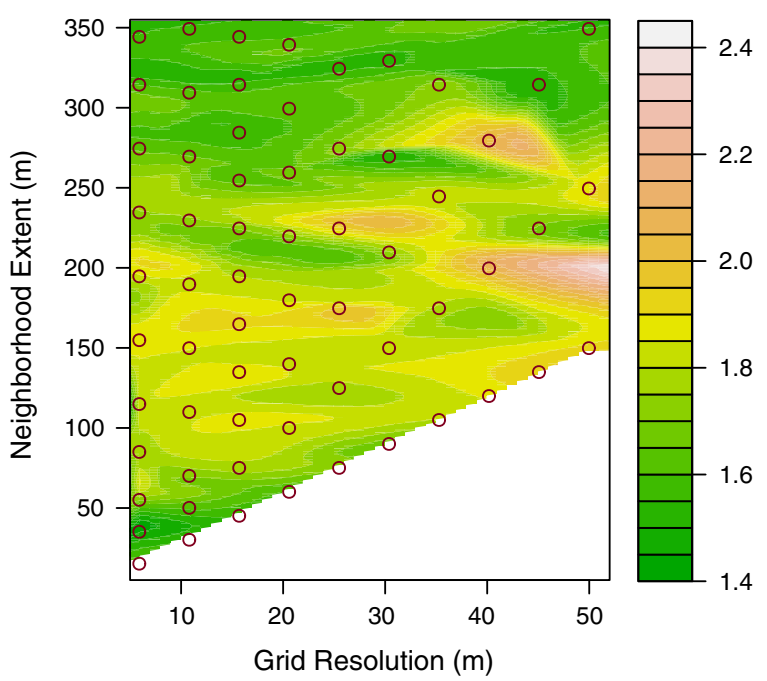

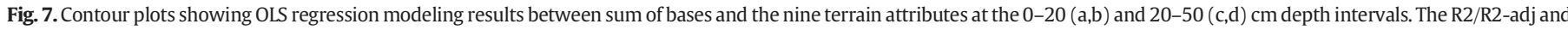
RMSE are presented for the $0-20 \mathrm{~cm}$ (a and b, respectively) and $20-50 \mathrm{~cm}$ (c and d, respectively) depth intervals.

Agriculture-Agricultural Research Service. It has been subjected to review by the National Health and Environmental Effects Research Laboratory's Western Ecology Division and approved for publication. Approval does not signify that the contents reflect the views of the Agencies, nor does mention of trade names or commercial products constitute endorsement or recommendation for use.

\section{Acknowledgments}

We would like to thank George McFadden for his cooperation and support, Matthew Fillmore for his expertise in sample design, soil pedon descriptions, and pedological interpretation. We would also like to thank NRCS and Dynamac staff for their help with field sampling and the NRCS National Laboratory for conducting all laboratory analyses.

\section{References}

Anderson, E., Thompson, J., Crouse, D., Austin, R., 2006. Horizontal resolution and data density effects on remotely sensed LIDAR-based DEM. Geoderma 132, 406-415.
Arrouays, D., Vion, I., Kicin, J., 1995. Spatial analysis and modeling of topsoil carbon storage in temperate forest humic loamy soils of France. Soil Sci. 159, 191-198.

Beaudette, D.E., Roudier, P., O'Geen, A.T., 2013. Algorithms for quantitative pedology: a toolkit for soil scientists. Comput. Geosci. 52, 258-268.

Beers, T., Dress, W.P.E, Wensel, L.C., 1966. Aspect transformation in site productivity research. Journal of Forestry 64, 691-692.

Bishop, T., Minasny, B., 2006. Digital soil-terrain modeling: the predictive potential and uncertainty, environmental soil-landscape modeling-Geographic Information Technologies and Pedometrics. pp. 185-213.

Bishop, T.F.A., McBratney, A.B., Laslett, G.M., 1999. Modelling soil attribute depth functions with equal-ara quadratic smoothing splines. Geoderma 91, 27-45.

Burt, R., 2004. Soil survey laboratory methods manual. Soil Surv. Investig. Rep. 735.

Chaplot, V., Walter, C., Curmi, P., 2000. Improving soil hydromorphy prediction according to DEM resolution and available pedological data. Geoderma 97, 405-422.

De Bruin, S., 1998. Soil-landscape modelling using fuzzy c-means clustering of attribute data derived from a digital elevation model (DEM). Geoderma 83, 17-33.

De Bruin, S., Stein, A., 1998. Soil-landscape modeling using fuzzy c-means clustering of attribute data derived from a digital elevation model (DEM). Geoderma 83, 17-33.

Gessler, P., Moore, I., McKenzie, N., Ryan, P., 1995. Soil-landscape modelling and spatial prediction of soil attributes. Int. J. Geogr. Inf. Syst. 9, 421-432.

Gessler, P.E., Chadwick, O.A., Chamran, F., Althouse, L., Holmes, K., 2000. Modeling soil landscape and ecosystem properties using terrain attributes. Soil Sci. Soc. Am. J. 64 2046-2056.

Grunwald, S., 2006. What do we really know about the space-time continuum of soillandscapes. In: Grunwald, S. (Ed.), Environmental Soil-Landscape Modeling-Geographic Information Technologies and Pedometrics. CRC Press, pp. 3-36. 
a) Total Carbon $(0-20 \mathrm{~cm}) R^{2}$ and $R^{2}$-adj
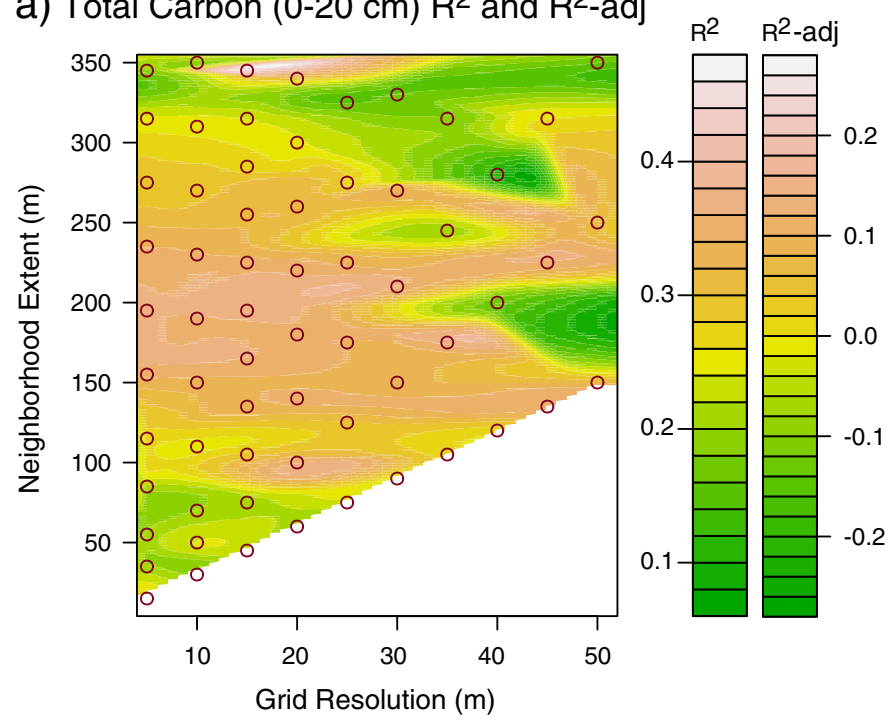

C) Total Carbon $(20-50 \mathrm{~cm}) R^{2}$ and $R^{2}-$ adj

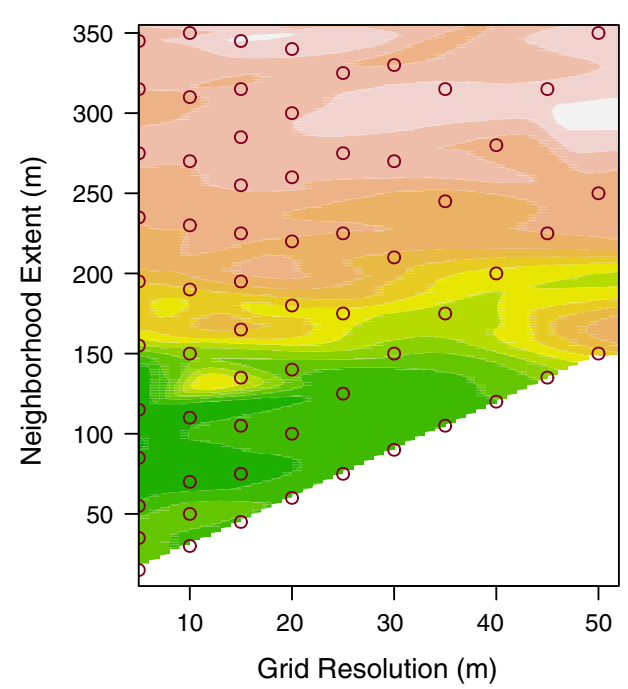

\section{b) Total Carbon $(0-20 \mathrm{~cm})$ RMSE}

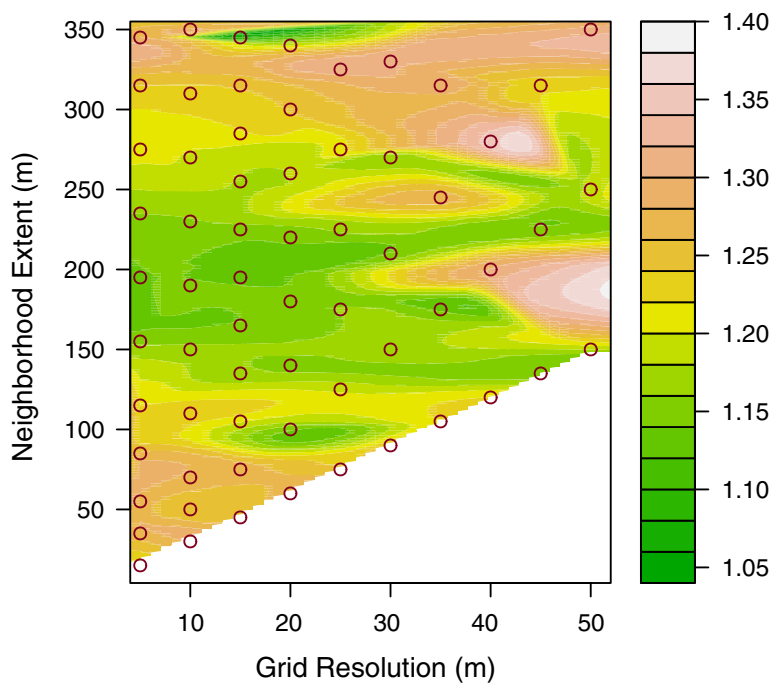

d) Total Carbon $(20-50 \mathrm{~cm})$ RMSE

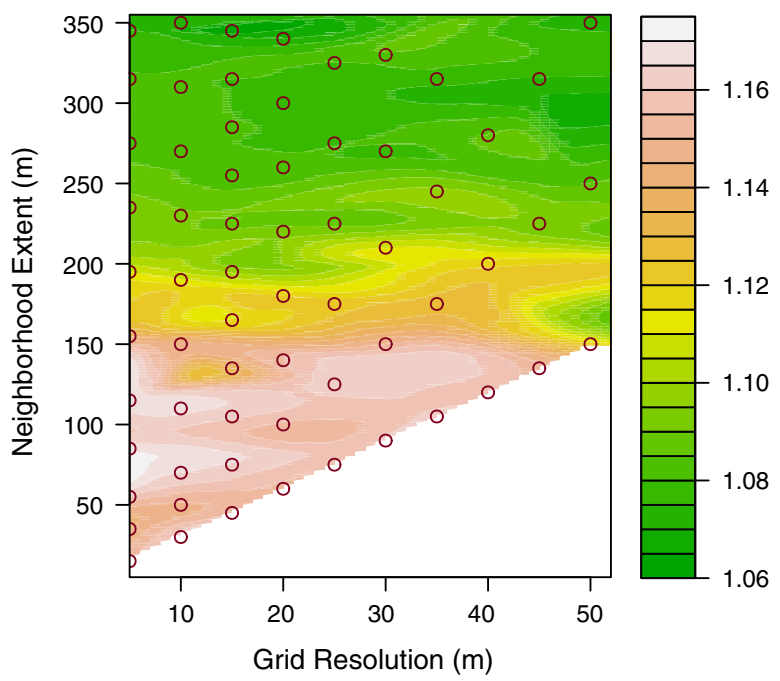

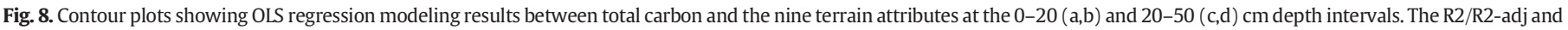
RMSE are presented for the $0-20 \mathrm{~cm}$ (a and b, respectively) and 20-50 cm (c and d, respectively) depth intervals.

Hijmans, R.J., Van Etten, J., 2011. Raster: Geographic Analysis and Modeling with Raster Data. R Package. R Package Version 1.9-67.

Huggett, R., 1975. Soil landscape systems: a model of soil genesis. Geoderma 13, 1-22.

Kim, D., Zheng, Y., 2011. Scale-dependent predictability of DEM-based landform attributes for soil spatial variability in a coastal dune system. Geoderma 164, 181-194.

Malone, B.P., McBratney, A.B., Minasny, B., Laslett, G.M., 2009. Mapping continuous depth functions of soil carbon storage and available water capacity. Geoderma 154, 138-152.

McKenzie, N., Austin, M., 1993. A quantitative Australian approach to medium and small scale surveys based on soil stratigraphy and environmental correlation. Geoderma 57, 329-355.

McKenzie, N., Ryan, P., 1999. Spatial prediction of soil properties using environmental correlation. Geoderma 89, 67-94.

McKenzie, N.J., Gessler, P.E., Ryan, P.J., O'Connell, D.A., 2000. The role of terrain analysis in soil mapping. In: Gallant, J.C., Wilson, J.P. (Eds.), Terrain Analysis Principles and Applications. John Wiley and Sons, pp. 245-265.

Moore, I., Gessler, G., Nielsen, G., Peterson, G., 1993. Soil attribute prediction using terrain analysis. Soil Sci. Soc. Am. J. 57, 443-452.

Park, S., Burt, T., 2002. Identification and characterization of pedogeomorphological processes on a hillslope. Soil Sci. Soc. Am. J. 66, 1897-1910.

Park, S., McSweeney, K., Lowery, B., 2001. Identification of the spatial distribution of soils using a process-based terrain characterization. Geoderma 249-272.

Park, S., Ruecker, G., Agyare, W., Akramhanov, A., Kim, D., Vlek, P., 2009. Influence of grid cell size and flow routing algorithm on soil-landform modeling. J. Korean Geogr. Soc. $44,122-145$.
Rapport, D.J., Costanza, R., McMichael, A.J., 1998. Assessing ecosystem health. Trends Ecol. Evol. 13, 397-402

Roecker, S., Thompson, J., 2010. Scale effects on terrain attribute calculation and their use as environmental covariates for digital soil mapping. In: Boettinger, J.L. (Ed.), Digital Soil Mapping: Bridging Research, Production, and Environmental Application. Spinger, pp. 55-66.

Ryan, PJ., McKenzie, N.J. O'Connell, D., Loughhead, A.N., Leppert, P.M., Jacquier, D., Ashton, L., 2000. Integrating forest soils information across scales: spatial prediction of soil properties under Australian forests. For. Ecol. Manag. 138, 139-157.

Scull, P., Franklin, J., Chadwick, O.A., McArthur, D., 2003. Predictive soil mapping: a review. Prog. Phys. Geogr. 27, 171-197.

Shi, X., Girod, L., Long, R., DeKett, R., Philippe, J., Burke, T., 2012. A comparison of LiDARbased DEMs and USGS-sourced DEMs in terrain analysis for knowledge-based digital soil mapping. Geoderma 170, 217-226.

Sinowski, W., Auerswald, K., 1999. Using relief parameters in a discriminant analysis to stratify geological areas with different spatial variability of soil properties. Geoderma 89, 113-128.

Smith, M.P., Zhu, A.-X., Burt, J.E., Stiles, C., 2006. The effects of DEM resolution and neighborhood size on digital soil survey. Geoderma 137, 58-69.

Thieken, A.H., Lücke, A., Diekkrüger, B., Richter, O., 1999. Scaling input data by GIS for hydrological modelling. Hydrol. Process. 13, 611-630.

Thompson, J., Bell, J., Butler, C., 2001. Digital elevation model resolution: effects on terrain attribute calculation and quantitative soil-landscape modeling. Geoderma 100, 67-89. 
Vaze, J., Teng, J., Spencer, G., 2010. Impact of DEM accuracy and resolution on topographic indices. Environ. Model Softw. 25, 1086-1098.

Walker, P., Hall, G., Protz, R., 1968. Relation between landform parameters and soil properties. Soil Sci. Soc. Am. J. 32, 101-104.

Wechsler, S., 2007. Uncertainties associated with digital elevation models for hydrologic applications: a review. Hydrol. Earth Syst. Sci. 1481-1500.
Wood, J., 1996. The Geomorphological Characterisation of Digital Elevation Models. University of Leicester, UK (185 pp.).

Zhang, W., Montgomery, D.R., 1994. Digital elevation model grid size, landscape representation, and hydrologic simulations. Water Resour. Res. 30, 1019-1028. 